\title{
Adhesion and host cell modulation: critical pathogenicity determinants of Bartonella henselae
}

\author{
Bettina Franz and Volkhard AJ Kempf
}

\begin{abstract}
Bartonella henselae, the agent of cat scratch disease and the vasculoproliferative disorders bacillary angiomatosis and peliosis hepatis, contains to date two groups of described pathogenicity factors: adhesins and type IV secretion systems. Bartonella adhesin A (BadA), the Trw system and possibly filamentous hemagglutinin act as promiscous or specific adhesins, whereas the virulence locus (Vir)B/NirD4 type IV secretion system modulates a variety of host cell functions. BadA mediates bacterial adherence to endothelial cells and extracellular matrix proteins and triggers the induction of angiogenic gene programming. The VirB/VirD4 type IV secretion system is responsible for, e.g., inhibition of host cell apoptosis, bacterial persistence in erythrocytes, and endothelial sprouting. The Trw-conjugation system of Bartonella spp. mediates host-specific adherence to erythrocytes. Filamentous hemagglutinins represent additional potential pathogenicity factors which are not yet characterized. The exact molecular functions of these pathogenicity factors and their contribution to an orchestral interplay need to be analyzed to understand $B$. henselae pathogenicity in detail.
\end{abstract}

\section{Introduction}

Bartonella henselae is a gram-negative, zoonotic pathogen with world-wide distribution. Cats have been identified as reservoir hosts but there is evidence that dogs might also serve as a primary reservoir $[1,2]$. In cats, $B$. henselae causes a long-lasting intraerythrocytic bacteraemia and the organism is transmitted between cats by cat fleas $[3,4]$. Transmission by other arthropods, such as ticks, has also been suggested [5,6]. Interestingly, the number of reservoir hosts has increased continuously (for overview see [7]).

$B$. henselae is the aetiologic agent of the cat scratch disease (CSD). The organism is transmitted from infected cats to humans by bites or scratches. In most cases, the onset of the disease is a unilateral lymphadenitis in the lymph draining region near the site of the scratch or bite which occurs 2-3 weeks after infection. Usually, CSD is self-limiting and patients do not require antibiotic treatment. However, the clinical course of a $B$. henselae infection can vary from asymptomatic infections towards severe and chronic illness which might cause difficulties in the laboratory diagnosis of such

\footnotetext{
* Correspondence: volkhard.kempf@kgu.de University hospital of the Johann Wolfgang Goethe-University, Institute for Medical Microbiology and Infection Control, Paul-Ehrlich-Strasse 40, Frankfurt am Main, D-60596, Germany
}

disease. In immunosuppressed patients (e.g., AIDS patients), $B$. henselae infections can result in proliferations of mainly capillary-sized vessels in the skin (bacillary angiomatosis) or liver (peliosis hepatis). The pathogen is detectable within these lesions, and bacterial eradication by antibiotic treatment results in regression of the angiomatous tumours [8,9]. Interestingly, current reports describe that $B$. henselae can also cause bacteremia in immunocompetent patients [10].

Although research with the slow growing and fastidious $B$. henselae is hampered by difficulties in performing molecular genetics and by the lack of suitable animal models, two essential pathogenicity factors of $B$. henselae have been identified and investigated in detail in recent years: (i) Bartonella adhesin A (BadA) which mediates adhesion to the extracellular matrix and mammalian host cells and (ii) the VirB/VirD4 type IV secretion system which modulates mammalian host cell functions by injecting Bartonella effector proteins (Beps) $[11,12]$. In addition, a further type IV secretion system (Trw-system), other adhesins and potentially filamentous hemagglutinins might also contribute to the pathogenicity of B. henselae [7]. This manuscript gives a brief overview of these pathogenicity factors and their possible interactions in the course of infection. 


\section{Bartonella adhesin A (BadA)}

Adherence to the host is one of the most important steps during bacterial infection processes. In $B$. henselae, this first and decisive adherence is provided by the trimeric autotransporter adhesin BadA [11] (see Figure 1). Trimeric autotransporter adhesins are widespread in alpha-, beta- and gamma-proteobacteria and play important roles in the pathogenicity of many gram-negative bacteria (e.g., Yersinia enterocolitica, Haemophilus influenzae, Moraxella catarrhalis, Neisseria meningitidis) $[13,14]$. Trimeric autotransporter adhesins are built in a characteristic trimeric, "lollipop"-like surface structure and share a modular organisation consisting of different domains [15]. The C-terminal membrane anchor is homologous throughout all trimeric autotransporter adhesins, forms trimers and provides the autotransport activity. During assembly, trimeric autotransporter adhesins are secreted into the periplasm via the secretory (Sec)-pathway and the membrane anchor forms a pore by building a trimeric 12-stranded beta-barrel in the outer membrane. Head and stalk domains are transported through the pore to the cell surface and the C-terminal part of the stalk locks the pore [16].

Monomeric BadA has a molecular weight of $328 \mathrm{kDa}$ (trimeric: $\sim 1.000 \mathrm{kDa}$ ) and an enormous length of $\sim 240 \mathrm{~nm}$ caused mainly by a long and highly repetitive stalk element. Experiments with a mutant strain lacking almost the whole stalk region suggest that the stalk plays a crucial role in fibronectin binding [17]. Additionally, BadA mediates bacterial autoagglutination, binding

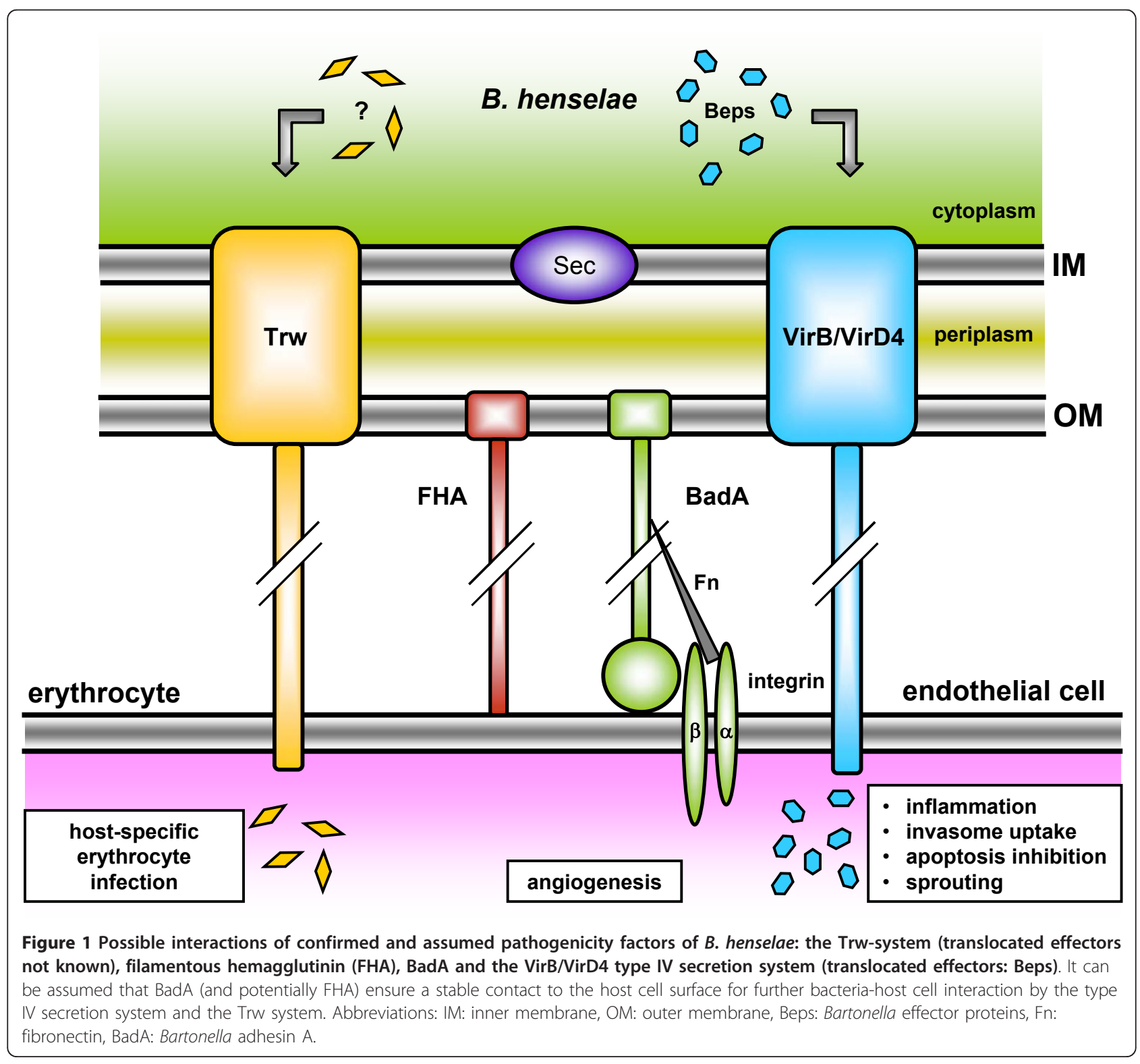


to extracellular matrix components (e.g., collagens, laminin), adhesion to host cells and the induction of proangiogenic host cell responses via the activation of hypoxia inducible factor (HIF)-1, the key transcription factor involved in angiogenesis, and the subsequent secretion of angiogenic cytokines [e.g., vascular endothelial growth factor (VEGF)] [11]. These functional properties were assigned to the head domain of BadA which consists of three subdomains: the N-terminal subdomain is homologous to the head of Y. enterocolitica adhesin A (YadA) which represents the best characterized trimeric autotransporter adhesin. A highly conserved, short sequence, the neck domain, acts as a linker for two other subdomains (Trp-Ring and GIN) [14,18]. So far, no particular biological functions have been assigned to these subdomains of the BadA head domain.

\section{Filamentous hemagglutinin}

Further to trimeric autotransporter adhesins, other adhesins like filamentous hemagglutinins are known to mediate adhesion to host cells in gram negative bacteria $[19,20]$. In contrast to trimeric autotransporter adhesins, the presence of filamentous hemagglutinin (FhaB) necessarily depends on a second partner (FhaC/HecB). After Sec-dependent secretion of both proteins to the periplasm, $\mathrm{FhaC} / \mathrm{HecB}$ forms a transmembrane beta-barrel that allows FhaB to cross the outer membrane. At the cell surface, the protein is further modified and reaches final maturity [21-23].

Analysis of the genome sequence of $B$. henselae revealed eight genes of different lengths encoding homologues of filamentous hemagglutinin (fhaB1-8), and four genes encoding homologues of their corresponding partner secretion proteins $(f h a C / h e c B 1-4)$ [24]. First and indirect experimental evidence for a potential role of filamentous hemagglutinin in infection process of human endothelial cells derived from a genome-wide transcriptional profiling of a $B$. henselae mutant lacking the response regulator BatR: together with its sensor partner BatS, BatR controlled the expression of horizontally transmitted gene sets critical for the diverse hostassociated life styles of $B$. henselae. Expression of $f h a C /$ $h e c B$ was reported to be upregulated by BatR, indicating a possible role of filamentous hemagglutinin in the process of adhesion to host cells [25]. Currently, there are no experimental data but only speculations on the role of filamentous hemagglutinin in the infection process with B. henselae [15].

\section{VirB/VirD4 type IV secretion system}

B. henselae adhesins might interact with other important pathogenicity factors like type IV secretion systems. Such secretion machineries span the inner and outer membrane of gram-negative bacteria and transfer bacterial effector proteins or DNA to a bacterial or eukaryotic recipient cell probably by a pilus or other surface- protruding filament [26]. The $B$. henselae VirB/VirD4 type IV secretion system (i) mediates rearrangements of the actin cytoskeleton resulting in the formation of bacterial aggregates on the cell surface that are subsequently internalized ("invasome" structure), (ii) triggers a proinflammatory phenotype via activation of nuclear factor (NF) $\kappa \mathrm{B}$ that in turn induces the secretion of interleukin- 8 and the expression of the cell adhesion molecules intercellular adhesion molecule (ICAM)-1 and E-selectin and (iii) is crucial for the inhibition of endothelial apoptosis [27]. Moreover, the VirB/ VirD4 type IV secretion system is crucially involved in establishing a chronic and bacteraemic infection of the host, as shown in a Bartonella tribocorum-rat infection model [12].

To date, seven Bartonella effector proteins (BepA-F) have been identified that are translocated by the type IV secretion system machinery [28]. BepA was found to protect endothelial cells from apoptosis [29] and promotes capillary sprouting in an three-dimensional endothelial spheroid infection model. Furthermore, BepG inhibits BepA dependent sprouting and, therefore, both proteins may control angiogenesis during $B$. henselae infections [30]. The combined action of BepC and BepF, but also of BepG itself, induces "invasome"mediated internalization by inhibiting bacterial endocytosis [31,32]. So far, it can be assumed that the VirB/ VirD4 type IV secretion system might interact functionally with BadA and the filamentous hemagglutinin. Potentially, these adhesins establish a first and close contact to the host cell surface and act as spacers providing the optimum distance between the bacterium and the host cell for subsequent protein translocation by the VirB/VirD4 type IV secretion system. Further experiments are required to understand the interaction of these key virulence factors in more detail.

\section{Trw type IV secretion system}

Beside the VirB/VirD4 type IV secretion system, the $B$. henselae genome sequence revealed genes for a second Trw type IV secretion system. Trw-deficient mutants of Bartonella tribocorum and Bartonella birtlesii were unable to establish a long-lasting bacteremia in their respective animal models. The Trw type IV secretion system was suggested to be essential for intracellular colonization of erythrocytes, whereas a role in infection of endothelial cells was not found [33]. Furthermore, the Trw system mediates host-specificity of erythrocyte infections [34]. Therefore, the Trw type IV secretion system of $B$. henselae might represent a further important pathogenicity factor for establishing chronic bacteremia in the primary (feline) host and possibly interacts 
with adhesins during the primary infection process, comparable to the VirB/VirD4 type IV secretion system.

\section{Conclusion}

B. henselae infections are of increasing interest in veterinary and human medicine. The pathogen causes a long-lasting bacteremia in its feline primary host and cat scratch disease, bacillary angiomatosis, peliosis hepatis and other diseases in humans. Only a limited knowledge about pathomechanisms operating in the course of a $B$. henselae infection exists. The best described pathogenicity factors are the VirB/D4 type IV secretion system, Bartonella adhesin A (BadA) and the Trw system. The trimeric autotransporter adhesin BadA ensures the contact of $B$. henselae to host cells and extracellular matrix proteins; filamentous hemagglutinin might also fulfill this function. Adhesion might be a necessary prerequisite to allow subsequent bacterial host cell modulation by the VirB/D4 type IV secretion systems. Currently it is not obvious whether similar pathomechanisms occur in both animal reservoir hosts and human patients. The development of a suitable $B$. henselae animal infection model, especially mimicking vasculoproliferative disorders, would greatly promote Bartonella research.

\section{Acknowledgements}

The work of V.K. is funded by the Deutsche Forschungsgemeinschaft (DFG) Publication of the CVBD6 thematic series has been sponsored by Bayer Animal Health $\mathrm{GmbH}$.

\section{Authors' contributions}

Both authors conceived the intellectual content and wrote the article. They also read and approved the final manuscript.

\section{Competing interests}

The authors declare that they have no competing interests.

Received: 15 February 2011 Accepted: 13 April 2011

Published: 13 April 2011

\section{References}

1. Rolain JM, Franc M, Davoust B, Raoult D: Molecular detection of Bartonella quintana, B. koehlerae, B. henselae, B. clarridgeiae, Rickettsia felis, and Wolbachia pipientis in cat fleas, France. Emerg Infect Dis 2003, 9: 338-342.

2. Keret D, Giladi M, Kletter Y, Wientroub S: Cat-scratch disease osteomyelitis from a dog scratch. J Bone Joint Surg Br 1998, 80: 766-767.

3. Rolain JM, La SB, Liang Z, Davoust B, Raoult D: Immunofluorescent detection of intraerythrocytic Bartonella henselae in naturally infected cats. J Clin Microbiol 2001, 39: 2978-2980.

4. Lappin MR, Griffin B, Brunt J, Riley A, Burney D, Hawley J, et al: Prevalence of Bartonella species, haemoplasma species, Ehrlichia species, Anaplasma phagocytophilum, and Neorickettsia risticii DNA in the blood of cats and their fleas in the United States. J Feline Med Surg 2006, 8: 85-90.

5. Angelakis E, Billeter SA, Breitschwerdt EB, Chomel BB, Raoult D: Potential for tick-borne bartonelloses. Emerg Infect Dis 2010, 16: 385-391.

6. Dietrich F, Schmidgen T, Maggi RG, Richter D, Matuschka FR, Vonthein R, et al: Prevalence of Bartonella henselae and Borrelia burgdorferi sensu lato DNA in Ixodes ricinus ticks in Europe. Appl Environ Microbiol 2010, 76: 1395-1398.

7. Kaiser PO, Riess T, O'Rourke F, Linke D, Kempf VA: Bartonella spp.: throwing light on uncommon human infections. Int J Med Microbiol 2011, 301: 7-15.
8. Relman DA, Loutit JS, Schmidt TM, Falkow S, Tompkins LS: The agent of bacillary angiomatosis. An approach to the identification of uncultured pathogens. N Engl J Med 1990, 323: 1573-1580.

9. Relman DA, Falkow S, LeBoit PE, Perkocha LA, Min KW, Welch DF, et al: The organism causing bacillary angiomatosis, peliosis hepatis, and fever and bacteremia in immunocompromised patients. N Engl J Med 1991, 324: 1514.

10. Breitschwerdt EB, Maggi RG, Lantos PM, Woods CW, Hegarty BC, Bradley JM: Bartonella vinsonii subsp. berkhoffii and Bartonella henselae bacteremia in a father and daughter with neurological disease. Parasit Vectors 2010, 3: 29.

11. Riess T, Andersson SG, Lupas A, Schaller M, Schäfer A, Kyme P, et al: Bartonella adhesin $\mathrm{A}$ mediates a proangiogenic host cell response. J Exp Med 2004, 200: 1267-1278

12. Schülein R, Dehio C: The VirB/VirD4 type IV secretion system of Bartonella is essential for establishing intraerythrocytic infection. Mol Microbiol 2002, 46: 1053-1067

13. Hoiczyk E, Roggenkamp A, Reichenbecher M, Lupas A, Heesemann J: Structure and sequence analysis of Yersinia YadA and Moraxella UspAs reveal a novel class of adhesins. EMBO J 2000, 19: 5989-5999.

14. Linke D, Riess T, Autenrieth IB, Lupas A, Kempf VA: Trimeric autotransporter adhesins: variable structure, common function. Trends Microbiol 2006, 14: 264-270

15. O'Rourke F, Schmidgen T, Kaiser PO, Linke D, Kempf VA: Adhesins of Bartonella spp. In Advances in Experimental Medicine and Biology. Bacterial Adhesion: Biology, Chemistry, and Physics. Edited by: Linke D, Goldman, A. Springer;

16. Henderson IR, Navarro-Garcia F, Desvaux M, Fernandez RC, a'Aldeen D: Type $\mathrm{V}$ protein secretion pathway: the autotransporter story. Microbiol Mol Biol Rev 2004, 68: 692-744.

17. Kaiser PO, Riess T, Wagner $C L$, Linke D, Lupas AN, Schwarz H, et al: The head of Bartonella adhesin A is crucial for host cell interaction of Bartonella henselae. Cell Microbiol 2008, 10: 2223-2234.

18. Barocchi MA, Masignani V, Rappuoli R: Opinion: Cell entry machines: a common theme in nature? Nat Rev Microbiol 2005, 3: 349-358.

19. Rojas $\mathrm{CM}$, Ham JH, Deng WL, Doyle JJ, Collmer A: HecA, a member of a class of adhesins produced by diverse pathogenic bacteria, contributes to the attachment, aggregation, epidermal cell killing, and virulence phenotypes of Erwinia chrysanthemi EC16 on Nicotiana clevelandii seedlings. Proc Natl Acad Sci USA 2002, 99: 13142-13147.

20. Nicholson TL, Brockmeier SL, Loving CL: Contribution of Bordetella bronchiseptica filamentous hemagglutinin and pertactin to respiratory disease in swine. Infect Immun 2009, 77: 2136-2146.

21. Clantin B, Delattre AS, Rucktooa P, Saint N, Meli AC, Locht C, et al: Structure of the membrane protein FhaC: a member of the Omp85-TpsB transporter superfamily. Science 2007, 317: 957-961.

22. Mazar J, Cotter PA: Topology and maturation of filamentous haemagglutinin suggest a new model for two-partner secretion. Mol Microbiol 2006, 62: 641-654

23. Coutte L, Willery E, Antoine R, Drobecq H, Locht C, Jacob-Dubuisson F: Surface anchoring of bacterial subtilisin important for maturation function. Mol Microbiol 2003, 49: 529-539.

24. Alsmark CM, Frank AC, Karlberg EO, Legault BA, Ardell DH, Canback B, et al: The louse-borne human pathogen Bartonella quintana is a genomic derivative of the zoonotic agent Bartonella henselae. Proc Natl Acad Sci USA 2004, 101: 9716-9721.

25. Quebatte M, Dehio M, Tropel D, Basler A, Toller I, Raddatz G, et al: The BatR/BatS two-component regulatory system controls the adaptive response of Bartonella henselae during human endothelial cell infection. J Bacteriol 2010, 192: 3352-3367.

26. Christie PJ, Atmakuri K, Krishnamoorthy V, Jakubowski S, Cascales E: Biogenesis, architecture, and function of bacterial type IV secretion systems. Annu Rev Microbiol 2005, 59: 451-485.

27. Schmid MC, Schülein R, Dehio M, Denecker G, Carena I, Dehio C: The VirB type IV secretion system of Bartonella henselae mediates invasion, proinflammatory activation and antiapoptotic protection of endothelial cells. Mol Microbiol 2004, 52: 81-92.

28. Schülein R, Guye P, Rhomberg TA, Schmid MC, Schroder G, Vergunst AC, et al: A bipartite signal mediates the transfer of type IV secretion substrates of Bartonella henselae into human cells. Proc Natl Acad Sci USA 2005, 102: 856-861 
29. Schmid MC, Scheidegger F, Dehio M, Balmelle-Devaux N, Schülein R, Guye $P$, et al: A translocated bacterial protein protects vascular endothelial cells from apoptosis. PLoS Pathog 2006, 2: e115.

30. Scheidegger F, Ellner $Y$, Guye P, Rhomberg TA, Weber H, Augustin HG, et al: Distinct activities of Bartonella henselae type IV secretion effector proteins modulate capillary-like sprout formation. Cell Microbiol 2009, 11: 1088-1101.

31. Rhomberg TA, Truttmann MC, Guye P, Ellner Y, Dehio C: A translocated protein of Bartonella henselae interferes with endocytic uptake of individual bacteria and triggers uptake of large bacterial aggregates via the invasome. Cell Microbiol 2009, 11: 927-945.

32. Truttmann MC, Rhomberg TA, Dehio C: Combined action of the type IV secretion effector proteins BepC and BepF promotes invasome formation of Bartonella henselae on endothelial and epithelial cells. Cell Microbiol 2011, 13: 284-299.

33. Seubert A, Hiestand R, de la Cruz F, Dehio C: A bacterial conjugation machinery recruited for pathogenesis. Mol Microbiol 2003, 49: 1253-1266.

34. Vayssier-Taussat M, Le RD, Deng HK, Biville F, Cescau S, Danchin A, et al: The Trw type IV secretion system of Bartonella mediates host-specific adhesion to erythrocytes. PLoS Pathog 2010, 6: e1000946.

doi:10.1186/1756-3305-4-54

Cite this article as: Franz and Kempf: Adhesion and host cell

modulation: critical pathogenicity determinants of Bartonella henselae.

Parasites \& Vectors 2011 4:54.

\section{Submit your next manuscript to BioMed Central} and take full advantage of:

- Convenient online submission

- Thorough peer review

- No space constraints or color figure charges

- Immediate publication on acceptance

- Inclusion in PubMed, CAS, Scopus and Google Scholar

- Research which is freely available for redistribution

Submit your manuscript at www.biomedcentral.com/submit
C Biomed Central 